\title{
Mechanism of apoptosis induction associated with ERK1/2 upregulation via goniothalamin in melanoma cells
}

\author{
SUPHAKORN TANGCHIRAKHAPHAN ${ }^{1}$, SUKANDA INNAJAK ${ }^{2}$, SIRINUN NILWARANGKOON ${ }^{2}$, \\ NUDJAREE TANJAPATKUL ${ }^{2}$, WILAWAN MAHABUSRAKUM ${ }^{3}$ and RAMIDA WATANAPOKASIN ${ }^{2}$ \\ ${ }^{1}$ Skin Center; ${ }^{2}$ Department of Biochemistry, Faculty of Medicine, Srinakharinwirot University, Bangkok 10110; \\ ${ }^{3}$ Department of Chemistry, Faculty of Science, Prince of Songkla University, Hat Yai, Songkhla 90112, Thailand
}

Received July 3, 2017; Accepted January 11, 2018

DOI: $10.3892 / \mathrm{etm} .2018 .5762$

\begin{abstract}
The present study aimed to investigate the effect of goniothalamin on apoptosis induction in the A375 melanoma cell line. Melanoma is a type of skin cancer with increased prevalence and no potential standard treatment. Goniothalamin is a plant, bioactive styrly-lactone, which has various bioactivities including anti-microbial, anti-inflammatory and anti-cancer. Apoptosis induction by goniothalamin has been studied in numerous cancer cell lines, however not in the melanoma cell line A375. The results of the MTT assay demonstrated that goniothalamin induced anti-proliferation in a dose dependent manner. Hoechst staining assay demonstrated that goniothalamin induced chromatin condensation and apoptotic bodies in A375 treated cells, and JC-1 staining revealed that goniothalamin induced mitochondrial membrane dysfunction in A375 cells. In addition, goniothalamin decreased the level of anti-apoptotic proteins myeloid cell leukemia 1, B cell lymphoma (Bcl)-2 and Bcl-extra large, whereas it increased the level of pro-apoptotic proteins, Bcl-2 Associated X, apoptosis regulator, t-BID and Bim in A375 treated cells. In addition, goniothalamin also increased active caspase-9, -7 and cleaved-poly (ADP-ribose) polymerase expression in A375 treated cells. Furthermore, phosphorylated (p)-pyruvate dehydrogenase kinase (PDK) 1 (Ser241) and p-RAC-alpha serine/threonine-protein kinase (Akt; Ser473) were decreased, however c-Jun and p-extracellular signal-regulated kinase (ERK)1/2 were increased upon goniothalamin treatment. These results suggest that goniothalamin has an effect, as anti-proliferation and apoptosis induction in A375 cells were associated with upregulated p-ERK1/2, c-Jun and downregulated p-PDK1 (Ser241), p-Akt (Ser473) in A375 cells. Therefore, goniothalamin may be a potential candidate for anti-cancer drug development for melanoma treatment.
\end{abstract}

Correspondence to: Professor Ramida Watanapokasin, Department of Biochemistry, Faculty of Medicine, Srinakharinwirot University, Sukhumvit 23, Bangkok 10110, Thailand

E-mail: ramidawa@yahoo.com

Key words: melanoma, goniothalamin, apoptosis, Akt, MAPK

\section{Introduction}

Skin cancer can be divided into two groups, non-melanoma skin cancer (NMSC) and malignant melanoma (MM). MM is the most related death skin cancer; incidence of melanoma is increasing worldwide (1-4). Melanoma developed from melanocyte, which is pigment-producing cell. There are several methods to treat melanoma depending on stage and severity of disease such as surgical excision, chemotherapy, radiotherapy, immunotherapy and biological therapy. All of them kill cancer cells but also kill normal cells, so new therapy is developing everyday (5).

Apoptosis or program cell death is an essential mechanism in multicellular organism. This process plays a critical role including normal cell turnover, development of embryo, functioning of the immune system, tissue homeostasis and elimination of damaged cells. During the early process of apoptosis, cells were initially described by its morphological characteristics including cell shrinkage, membrane blebbing, chromatin condensation and nuclear fragmentation. Abnormal apoptosis induces the processes of oncogenesis including initiation, progression and metastasis in abnormal cell. Recently, there are studies about apoptosis with cancercells, which studied about signaling process in cell (6-10).

Goniothalamin is extracted from root and bark of plant in family Annonaceae genus Goniothalamus. Studies show effect of goniothalamin as apoptotic agent and anti-proliferative agent in cancer cell, antibiotics, and antifungal $(11,12)$. Recent research has demonstrated that goniothalamin showed cytotoxicity and apoptosis induction in various tumor cell lines. However, the study of goniothalamin in MM has not yet been reported.

In the present study, we found that goniothalamin inhibited cell proliferation and induce apoptosis associated with mitochondria dysfunction, caspase activation, and the upregulation of c-Jun, p-p38 and p-ERK1/2, but downregulation of Akt signaling pathway in melanoma A375 cells.

\section{Materials and methods}

Materials. RPMI-1640 medium were purchased from Gibco (Thermo Fisher Scientific, Inc., Waltham, MA, USA). Hoechst 33342, 3-(4,5-dimethylthaiazol-2-yl)-2,5-diphenyltetrazolium 
bromide (MTT), JC-1 (5,5',6,6'-tetrachloro-1,1',3,3'-tetraeth yl-imidacarbocyanine iodide) and phenylmethylsulphonylfluoride (PMSF) were purchased from Sigma-Aldrich (Merck KGaA, Darmstadt, Germany). DMSO was purchased from Calbiochem (San Diego, CA, USA). Guava Cell Cycle ${ }^{\circledR}$ reagent for cell cycle analysis and fetal bovine serum (FBS) were purchased from Merck KGaA. MEK1/2 inhibitor (U0126) was purchased from Cell Signaling Technology, Inc. (Danvers, MA, USA). Goniothalamin was obtained from Assoc. Prof. Wilawan Mahabusarakam, Faculty of Science, Prince of Songkla University (Hat Yai, Thailand) in purified powder form (13).

Cell culture. MM cell line A375 was obtained from the American Type Culture Collection (ATCC; Manassas, VA, USA). Cells were maintained as a monolayer in RPMI-1640 supplemented with 10\% FBS (GE Healthcare, UK), $100 \mathrm{U} / \mathrm{ml}$ penicillin and $100 \mu \mathrm{g} / \mathrm{ml}$ streptomycin (PAA Laboratories, Pasching, Austria). The cells were cultured in $5 \% \mathrm{CO}_{2}$ at $37^{\circ} \mathrm{C}$ and subcultured 2-3 times/week.

Cell proliferation and cell viability assays. MTT assay was used to determine the cytotoxicity of goniothalamin. A375 cells were seeded in a 96-well plate at $5 \times 10^{3}$ cells/well and allowed to grow for $24 \mathrm{~h}$. Then, cells were treated with goniothalamin at $0.1,0.3,0.5,1,3,5$ and $10 \mu \mathrm{g} / \mathrm{ml}$ for $24 \mathrm{~h}$, whereas the control group was treated with $0.5 \%$ DMSO. After incubation, $100 \mu \mathrm{l}$ of $0.5 \mathrm{mg} / \mathrm{ml}$ MTT solution was added to each well and incubated for $2-4 \mathrm{~h}$ at $37^{\circ} \mathrm{C}$, then supernatant was removed and DMSO was added to solubilize the formazan crystals. The absorbance was measured by using a microplate reader at $570 \mathrm{~nm}$ (Multiskan EX; Thermo Electron Corp., Vantaa, Finland), and the $\mathrm{IC}_{50}$ value was calculated by using the GraphPad Prism 3.03 (GraphPad Software, Inc., San Diego, CA, USA).

Nuclear morphological staining with Hoechst 33342. A375 cells were seeded at $4 \times 10^{5}$ cells/well for $24 \mathrm{~h}$. Then, the cells were treated with 3,5 and $10 \mu \mathrm{g} / \mathrm{ml}$ goniothalamin for $24 \mathrm{~h}$, while, the control group was treated with $0.5 \%$ DMSO. After incubation, cells were stained with $5 \mu \mathrm{M}$ Hoechst 33342 for $30 \mathrm{~min}$ at $37^{\circ} \mathrm{C}$ and examined under a fluorescence microscope (IX73; Olympus, Tokyo, Japan).

Cell cycle analysis. To examine apoptosis induction via upregulation of sub-G1 population, flow cytometry was carried out. Cells were treated with 3,5 and $10 \mu \mathrm{g} / \mathrm{ml}$ goniothalamin for $24 \mathrm{~h}$ and $0.5 \%$ DMSO was used as the control group. Upon treatment, cells were washed with PBS and fixed with ice cold $70 \%$ ethanol at $4^{\circ} \mathrm{C}$ for more than $1 \mathrm{~h}$. After fixation, cells were stained according to the manufacturer's instructions (Guava Cell Cycle ${ }^{\circledR}$ reagent from Merck KGaA). The DNA content was observed by Guava easyCyte ${ }^{\mathrm{TM}}$ flow cytometer and GuavaSoft $^{\mathrm{TM}}$ software (Merck KGaA).

Measurement of mitochondrial membrane potential $(\Delta \Psi m)$. JC-1 was used to determine the function of the $\Delta \Psi \mathrm{m}$, which specific to mitochondria that is incorporated into the mitochondrial membrane. A375 cells were seeded at $3 \times 10^{5} /$ well for $24 \mathrm{~h}$. Then, cells were treated with 3,5 and $10 \mu \mathrm{g} / \mathrm{ml}$

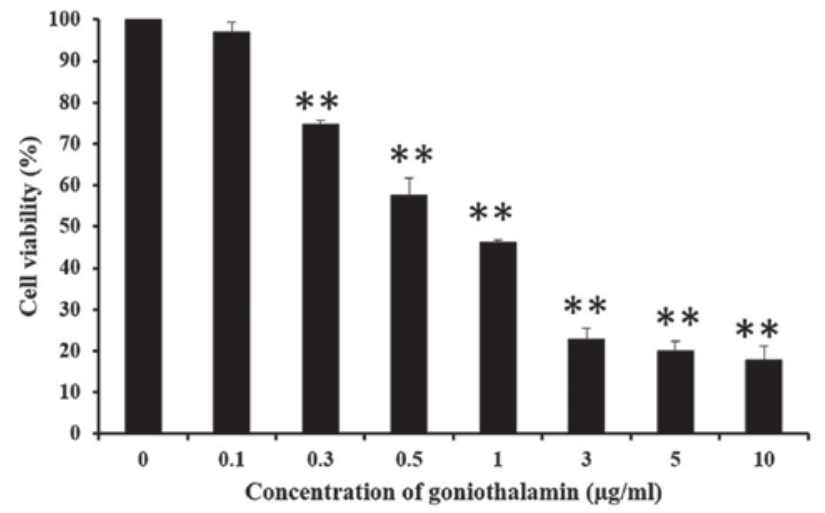

Figure 1. Effect of goniothalamin on cell viability following treatment with different concentrations of goniothalamin for $24 \mathrm{~h},{ }^{* *} \mathrm{P}<0.01$ significantly compared with the control.

goniothalamin for $24 \mathrm{~h}$, whereas the control group was treated with $0.5 \%$ DMSO. Cells were stained with $5 \mu \mathrm{g} / \mathrm{ml}$ of JC- 1 in the dark at $37^{\circ} \mathrm{C}$ for $10 \mathrm{~min}$ and washed with PBS for 3 times before analysis by fluorescence microscopy.

Western blot analysis. A375 cells were seeded at $3 \times 10^{5} /$ well for $24 \mathrm{~h}$. Cells were treated with 3,5 and $10 \mu \mathrm{g} / \mathrm{ml}$ goniothalamin for $24 \mathrm{~h}$, whereas the control group was treated with $0.5 \%$ DMSO and harvested at designated time points. The pellet cells were lysed with RIPA lysis buffer $(50 \mathrm{mM}$ Tris-HCL, pH 7.5, 5 mM EDTA, $250 \mathrm{mM} \mathrm{NaCl}, 0.5 \%$ Triton X-100) supplemented complete mini protease inhibitor cocktail (Roche Diagnostics GmbH, Mannheim, Germany). Protein expression by using western blot analysis was carried out according to a previously reported protocol (13).

Statistical analysis. All data presented were obtained from at least three independent experiments and were presented as mean \pm standard deviation (SD). Statistical significance was assessed by one-way analysis of variance (ANOVA). Statistical analysis was performed by using SPSS statistical software package (version 15; SPSS, Inc., Chicago, IL, USA) also carried out using the software GraphPad Prism 3.03 (GraphPad Software, Inc., La Jolla, CA, USA). The western blotting band intensity was quantified by Image J densitometer.

\section{Results}

The effect of goniothalamin on cell anti-proliferation and apoptosis induction in A375 cells. MTT assay was used to determine the anti-proliferation activity of goniothalamin in A375 cells. The results showed that goniothalamin inhibited cell proliferation in a dose-dependent manner in $\mathrm{A} 375$ treated cells with the $\mathrm{IC}_{50}$ value was $1.7 \pm 0.627 \mu \mathrm{g} / \mathrm{ml}$ (Fig. 1). Hoechst 33342 staining was used to determine the nuclear morphological changes mediated apoptosis. Morphological changes in apoptotic cell include chromatin condensation and apoptotic bodies. Hoechst 33342 is a fluorescence dye and a cell-permeable DNA stain used for labeling DNA, although the dyes can bind to all nucleic acid enhancing fluorescence considerably (14). The results 
A Goniothalamin $(\mu \mathrm{g} / \mathrm{ml})$

0

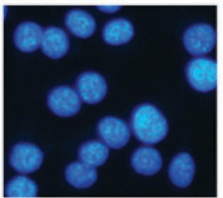

5

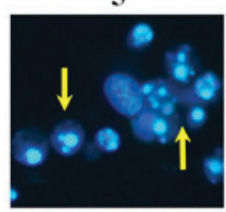

3

10
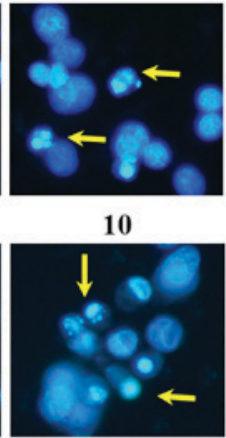

C Goniothalamin $(\mu \mathrm{g} / \mathrm{ml})$

0

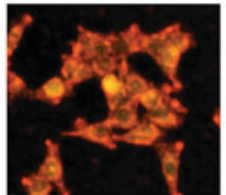

5

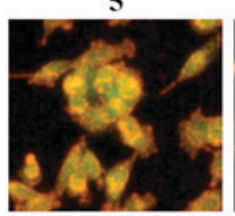

3

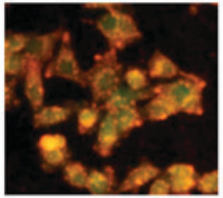

10

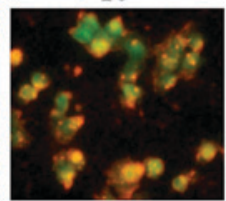

B

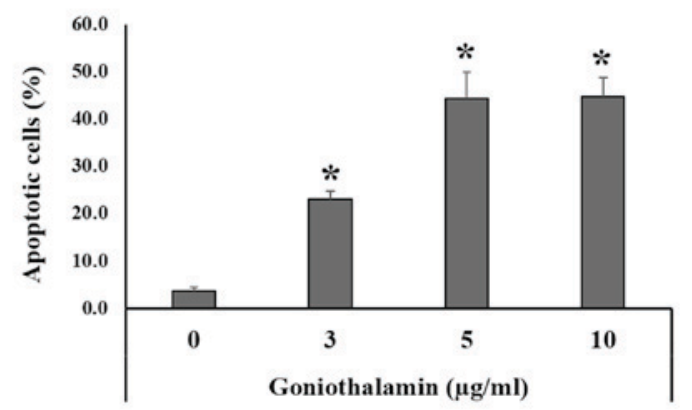

D

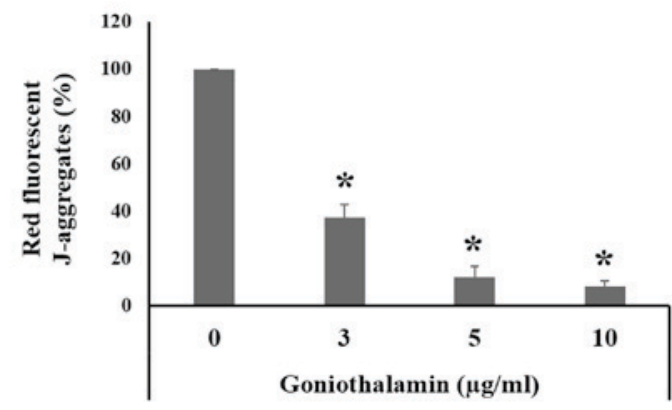

Figure 2. Effect of goniothalamin on apoptosis induction. (A) Effects of goniothalamin on nuclear condensation of A375 cells. Cells were treated with 3, 5 , and $10 \mu \mathrm{g} / \mathrm{ml}$ goniothalamin for $24 \mathrm{~h}$ and then stained with Hoechst 33342 and examined under a fluorescent microscope (magnification, $\mathrm{x} 40$ ). (B) Percentage of apoptotic cells of A375 goniothalamin treated cells compared with untreated cells. (C) The effect of gonothalamin on mitochondrial membrane potential in A375 cells. Cells were treated with 3,5 and $10 \mu \mathrm{g} / \mathrm{ml}$ goniothalamin for $24 \mathrm{~h}$. (D) Percentage of red fluorescent J-aggregates of A375 goniothalamin treated cells compared with untreated cells (magnification, $\mathrm{x} 40$ ), ${ }^{*} \mathrm{P}<0.05$ significantly compared with the control.

revealed that goniothalamin induced chromatin condensation and apoptotic bodies in A375 cells following treatment with goniothalamin (Fig. 2A). Our results showed that goniothalamin significantly induced apoptotic cells at 3,5 and $10 \mu \mathrm{g} / \mathrm{ml}$ $(\mathrm{P}<0.05$; Fig. 2B). This result suggested that goniothalamin could induce apoptosis in A375 cells.

Mitochondrial membrane potential $(\Delta \Psi m)$. During apoptosis, mitochondria was disturbed by pro-apoptotic proteins activation leading to the loss of $\Delta \Psi \mathrm{m}$. JC-1 staining was carried out to measure the $\Delta \Psi \mathrm{m}$. In normal cells with high $\Delta \Psi \mathrm{m}, \mathrm{JC}-1$ forms $\mathrm{J}$-aggregates complexes as shown in red fluorescence. Whereas, apoptotic cells with low $\Delta \Psi \mathrm{m}, \mathrm{JC}-1$ remains in the monomeric form as shown in green fluorescence (15). Our study showed that goniothalamin significantly induced the loss of $\Delta \Psi \mathrm{m}$ in A375 treated cells showing decreased red fluorescence comparing with the control cells $(\mathrm{P}<0.05$; Fig. 2C and D). This result indicated that goniothalamin induced apoptosis through mitochondria dysfunction in A375 treated cells.

Cell cycle distribution. To further verify the inhibitory effect of goniothalamin on apoptosis induction, cells were stained with PI and histogram analysis-related DNA contents were measured by flow cytometry. The treatment of A375 cells with goniothalamin at $3 \mu \mathrm{g} / \mathrm{ml}$ for 24 and $48 \mathrm{~h}$ showed increasing of sub-G1 population peak to 6.16 and $10.07 \%$, respectively, whereas the control cells showed $0.84 \%$ of sub-G1 population (Fig. 3). This result confirmed that goniothalamin induced cell death by apoptosis induction in A375 treated cells.

Bcl-2 family, caspase-7, caspase-9 and cleaved-PARP expression. The results showed that goniothalamin decreased the level of anti-apoptotic proteins Mcl-1, Bcl-2 and Bcl-xL in A375 treated cells $(\mathrm{P}<0.05$; Fig. $4 \mathrm{~A}$ and $\mathrm{B})$, whereas increased the level of pro-apoptotic proteins Bax, t-BID and Bim in A375 treated cells $(\mathrm{P}<0.05$; Fig. $4 \mathrm{~A}$ and $\mathrm{C})$. In addition, goniothalamin induced caspase-9, caspase-7 and cleaved-PARP activation in A375 treated cells ( $\mathrm{P}<0.05 ;$ Fig. 5A and B). The results indicated that goniothalamin could induce apoptosis via intrinsic pathway.

Effect of goniothalamin on AKT signaling pathway. AKT signaling pathway is one of the most important pathways, which promote cell proliferation, cell growth, transcription and cell migration. The results showed that goniothalamin downregulated p-PDK1 (Ser241) and total Akt indicating that goniothalamin could inhibit A375 cell survival $(\mathrm{P}<0.05$; Fig. 5A and $\mathrm{C})$.

The effect of goniothalamin on MAPK signaling pathway. MAPK signaling pathway is the pathway that involved both apoptosis and cell survival. Upon treatment with 

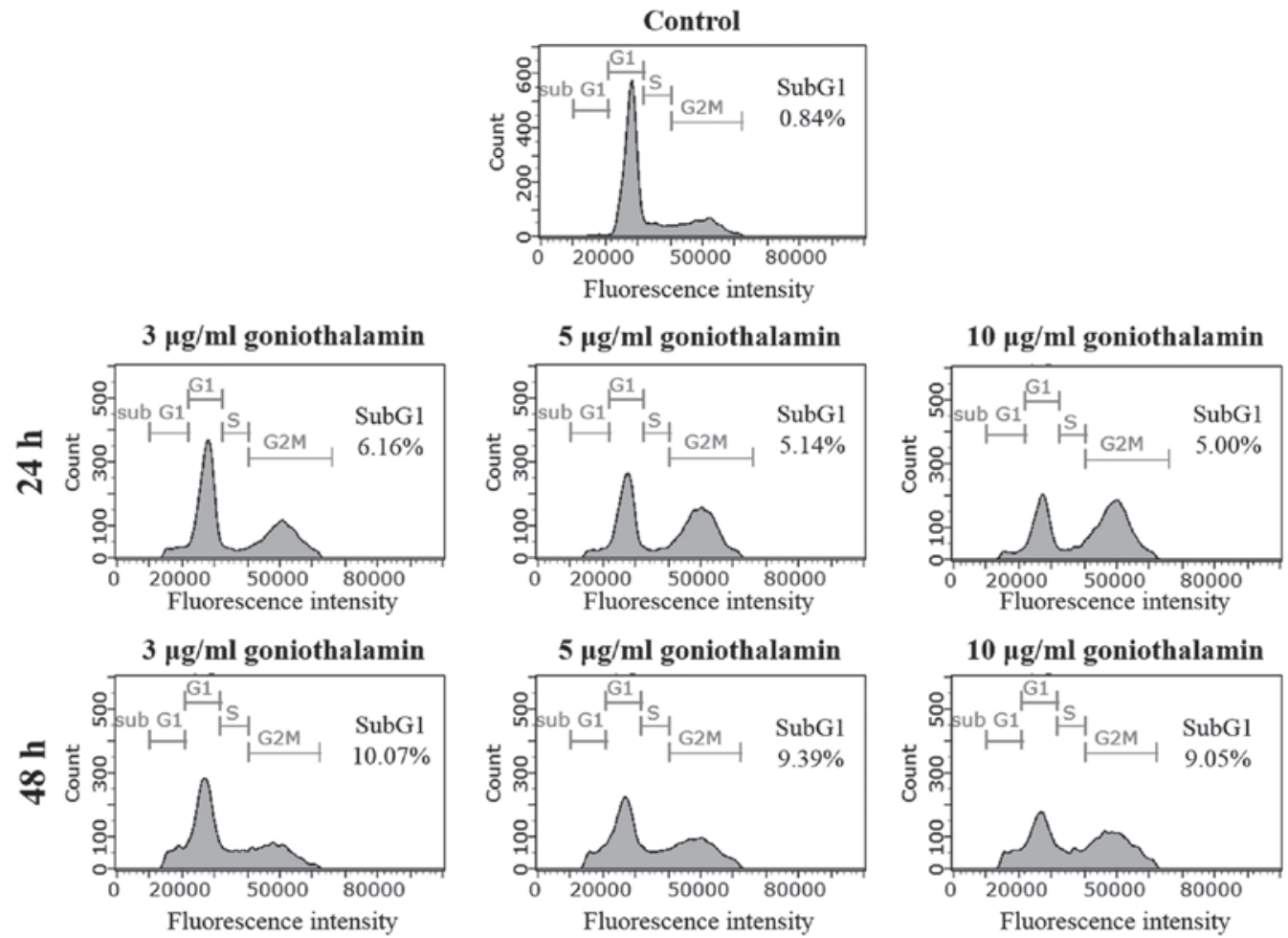

Figure 3. Effect of goniothalamin on cell cycle distribution. The sub G1 peak formed with reduced DNA content represented the presence of apoptotic cells. The mean apoptotic population of A375 cells was $0.84 \%$ under the control condition, while increasing to 6.16 and $10.07 \%$ upon treatment with $3 \mu \mathrm{g} / \mathrm{ml}$ goniothalamin for 24 and $48 \mathrm{~h}$, respectively.

A

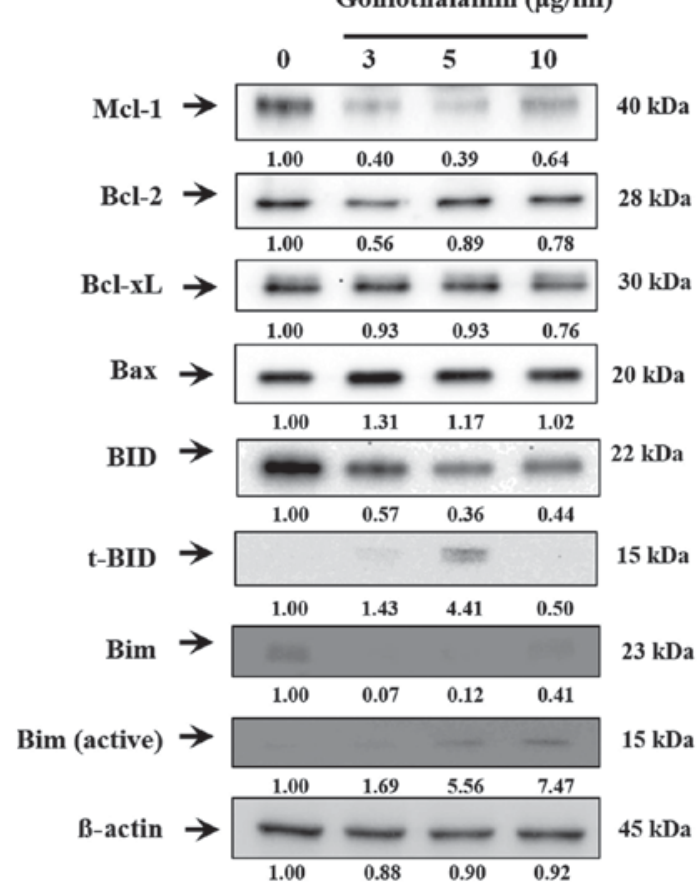

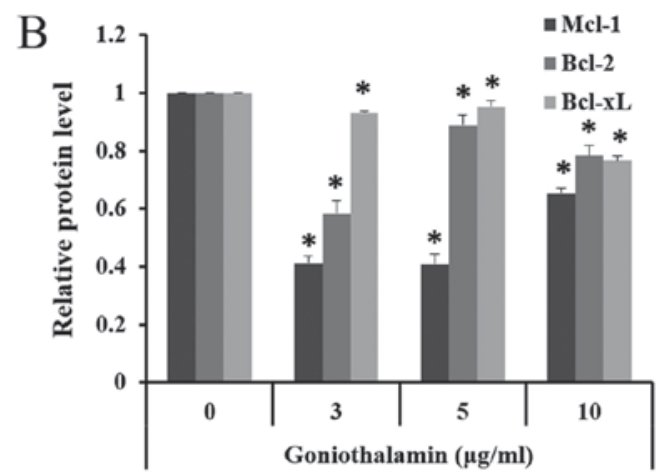

C

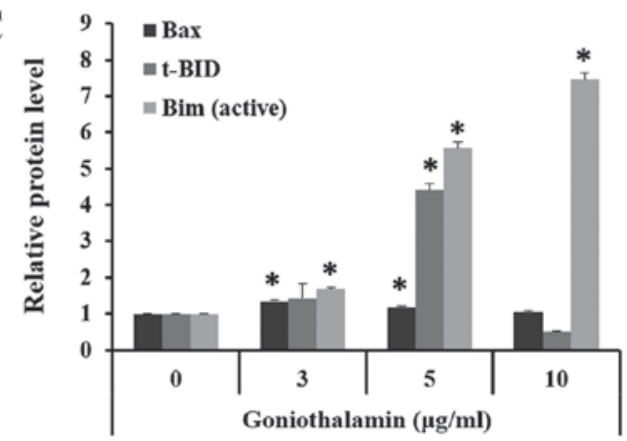

Figure 4. Effect of goniothalamin on Bcl-2 family protein expression. Cells were treated with 3, 5, and $10 \mu \mathrm{g} / \mathrm{ml}$ goniothalamin for $24 \mathrm{~h}$. (A) Effect of goniothalamin on anti-apoptotic and pro-apoptotic proteins in A375 cells were determined by western blot analysis. (B) Relative protein level of anti-apoptotic proteins. (C) Effect of goniothalamin on pro-apoptotic proteins in A375 cells were determined by western blot analysis. $\beta$-actin was used as an internal control, ${ }^{*} \mathrm{P}<0.05$ significantly compared with the control.

goniothalamin, the level of c-Jun, p-ERK1/2 and p-p38/p38 ratio were increased $(\mathrm{P}<0.05$; Fig. $6 \mathrm{~A}$ and $\mathrm{B})$. These results indicated that goniothalamin induced apoptosis via MAPK signaling pathway. In order to determine the effects of 

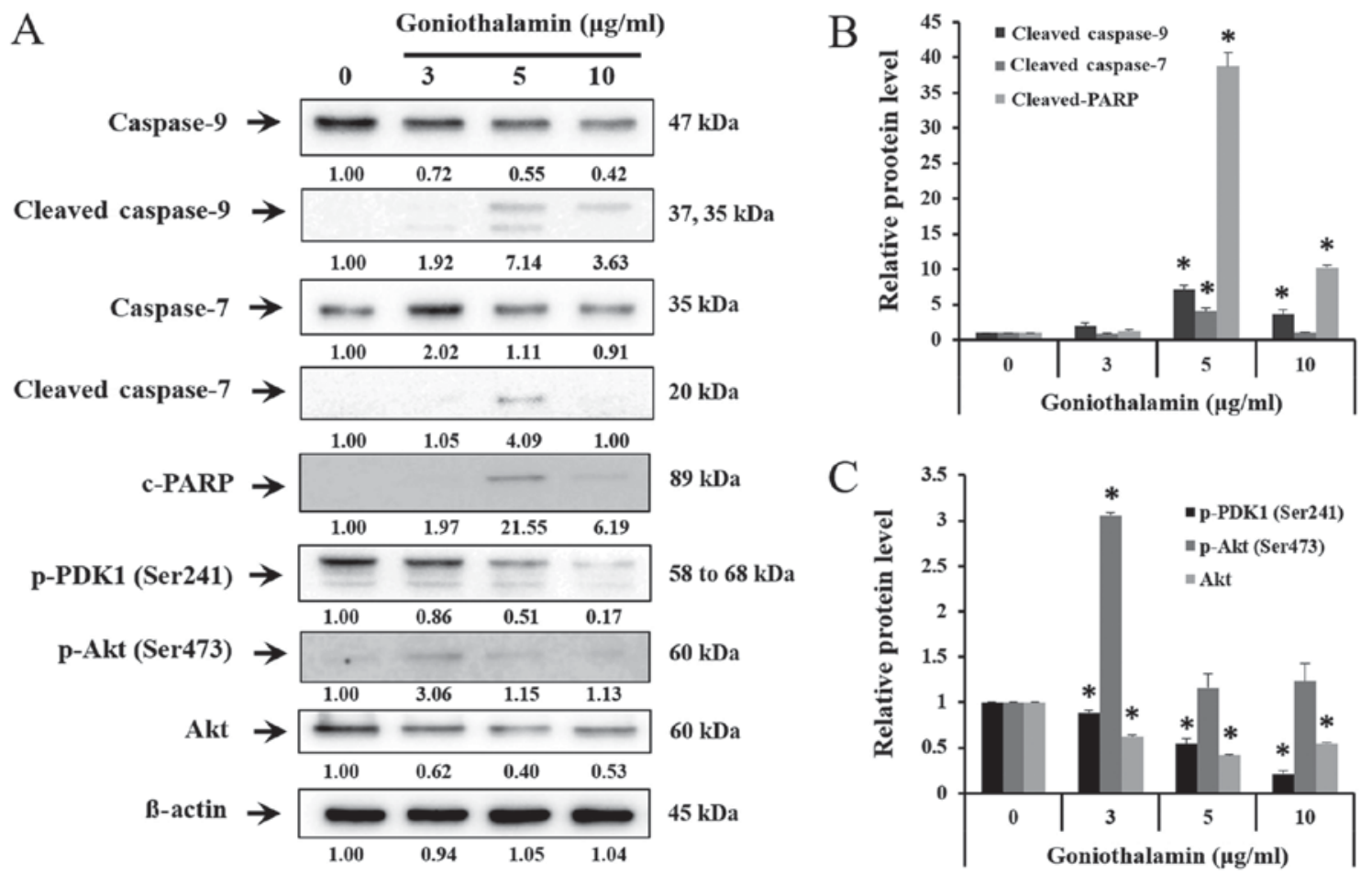

Figure 5. Effect of goniothalamin on caspase, cleaved-PARP induction and Akt signaling molecules. Cells were treated with 3,5 , and $10 \mu \mathrm{g} / \mathrm{ml}$ goniothalamin for $24 \mathrm{~h}$. (A) Effect of goniothalamin on caspase-9, -7, cleaved-PARP, p-PDK1, p-Akt at Ser473 and total Akt proteins in A375 cells were determined by western blot analysis. (B) Relative protein level of cleaved-caspase-9, cleaved-caspase-7 and cleaved-PARP proteins. (C) Relative protein level of p-PDK1, p-Akt and Akt proteins. $\beta$-actin was used as an internal control, ${ }^{*} \mathrm{P}<0.05$ significantly compared with the control.
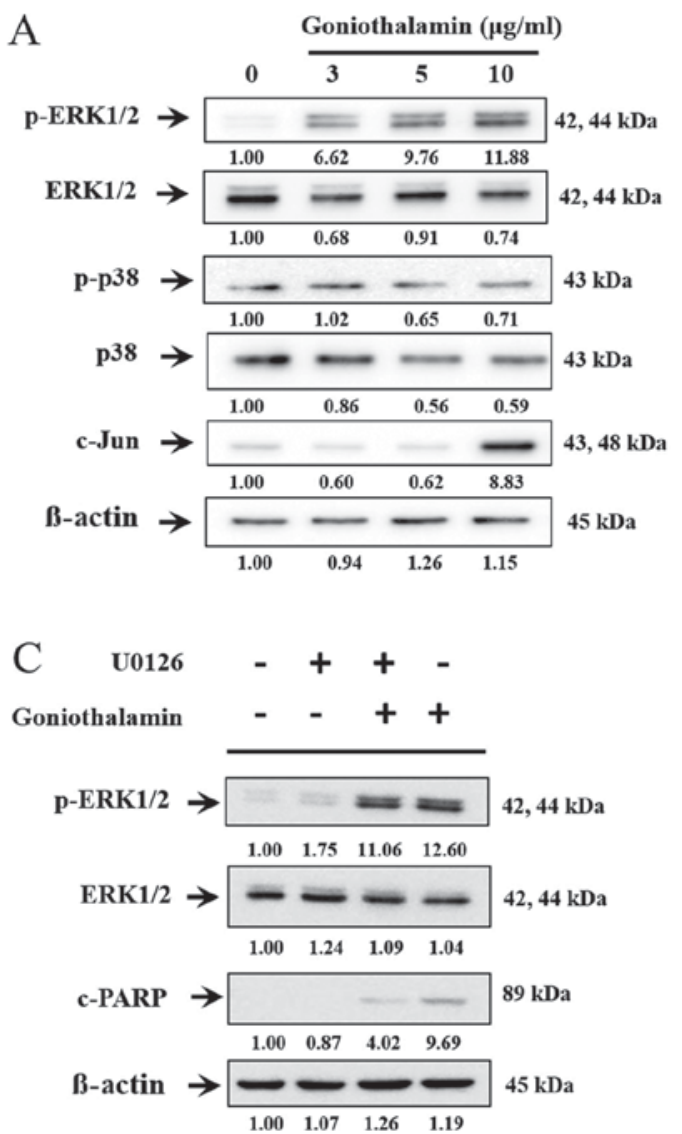

B

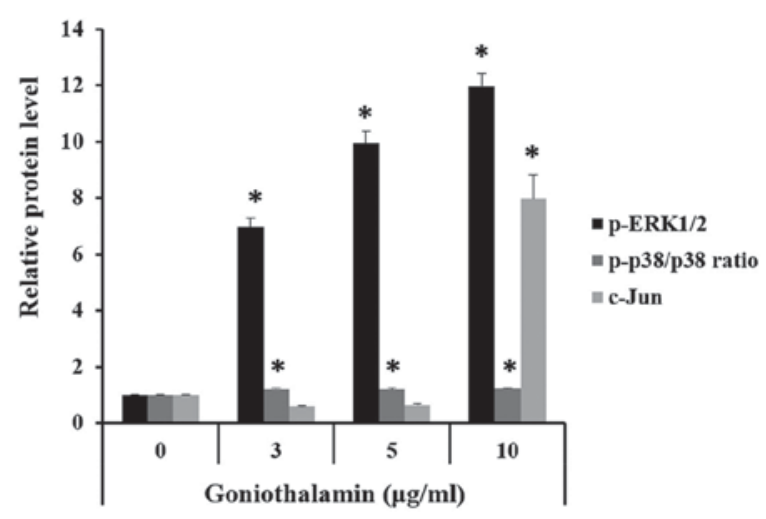

$\mathrm{D}$

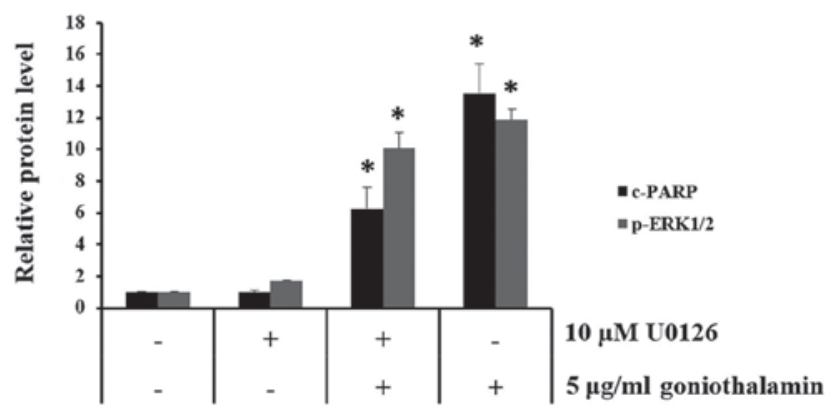

Figure 6. Effects of goniothalamin on phosphorylation of MAPK signaling in A375 cells. (A) Cells were treated with 3, 5, and $10 \mu \mathrm{g} / \mathrm{ml}$ goniothalamin for $24 \mathrm{~h}$ and examined by Western blot analysis. (B) Relative protein level of p-ERK1/2, c-Jun and p-p38/p38 ratio (C) U0126, MEK1/2 inhibitor was used as a positive control compared with the goniothalamin treatment. (D) Relative protein level of p-ERK1/2 and cleaved-PARP. $\beta$-actin was used as an internal control, ${ }^{*} \mathrm{P}<0.05$ significantly compared with the control. 
p-ERK1/2 on apoptosis induction by goniothalamin in A375 cells, MEK1/2 inhibitor (U0126) was used. The result showed that U0126 simultaneously blocked p-ERK1/2, in contrast, co-treatment between U0126 and goniothalamin showed upregulation of $\mathrm{p}$-ERK1/2 and cleaved-PARP indicating that goniothalamin induced apoptosis through ERK1/2 signaling $(\mathrm{P}<0.05$; Fig. 6C and D). These results suggested that goniothalamin induced apoptosis in A375 cells by promoting cell death through $\mathrm{p}-\mathrm{ERK} 1 / 2$ activation.

\section{Discussion}

In this study, A375 cell line was used as a model for MM. MM is one of the most related death skin cancer which originated from melanocyte (pigment cells). The treatments of MM depending on stage and severity of disease, surgical excision is the main therapy of MM. However adjuvant therapy is needed for advanced stage disease but most of therapy have side effects and not significantly increase survival rate in patients.

Recent research group has demonstrated that goniothalamin showed cytotoxicity and apoptosis induction in various tumor cell lines, H1299 (non-small cell lung cancer) (16), HepG2 (human hepatoblastoma) (17), SK-BR-3 (human breast cancer) (13), A549 (lung carcinoma) (18), HL60 (promyelocytic leukemia) $(19,20)$, SGC7901 (stomach cancer) (21), HT29 (colon cancer) $(22,23)$, HeLa (cervical cancer) (24), and MDA-MB231 (invasive breast cancer) (25). However, the study of goniothalamin in MM have not yet been reported.

The results showed goniothalamin inhibited A375 cell growth in a dose-dependent manner. Innajak et al demonstrated that goniothalamin inhibited SK-BR-3 cell growth in a time- and dose-dependent manner with an $\mathrm{IC}_{50}$ value of $10 \pm 0.45 \mu \mathrm{g} / \mathrm{ml}(13)$. At $72 \mathrm{~h}$, goniothalamin completely inhibited cell viability in MDA-MB-231 with an $\mathrm{IC}_{50}$ value of about $1.46 \mu \mathrm{M}$ (25).

Hoechst staining was used to confirm nuclear morphological changes via apoptosis induction. Hoechst staining showed condensed chromatin and apoptotic bodies in the A375 cells after treatment with goniothalamin (Fig. 2A). In other cell line, Chen et al reported that after treat MDA-MB-231 cells with $30 \mu \mathrm{M}$ goniothalamin for $48 \mathrm{~h}$, chromatin condensation and nuclear fragmentation were detected (25).

Moreover the JC-1 staining assay showing significantly decreased red fluorescence while increased green indicating that the loss of $\Delta \Psi \mathrm{m}$ and leading to apoptosis induction (Fig. 2C and D).

To confirm signaling pathway of apoptosis induction, Bcl-2 family proteins, caspase proteins, Akt and MAPK pathway were analyzed by western blotting.

The anti-apoptotic proteins Bcl-2 family protein, Bcl-2, Mcl-1 and Bcl-xL was deceased (Fig. 4A) whereas pro-apoptotic proteins Bax, t-BID and Bim were increased upon treatment with goniothalamin (Fig. 4A). In addition, there are two types of caspase, initiator and effector caspase, caspase-9 (initiator caspase) can activate caspase-7 (effector caspase) and deactivate PARP, which is DNA repairing protein. The results showed that caspase-7 and caspase-9 were increased which then induced cleaved-PARP activation (Fig. 5A). These results correlated with previous study revealing that goniothalamin induced apoptosis in different cancer cell types including HeLa (26), SK-BR-3 (13), Colo 205, SW480 and LoVo cells (27).
Akt is signaling pathway that promotes cell growth and anti-apoptosis. From previous studies, goniothalamin down regulated phosphorylated Akt at Ser473, Thr308 and total Akt in SK-BR-3 cells leading to apoptosis induction (13). These studies showed the decrease of p-PDK1 (Ser241) and total Akt (Fig. 5A) indicating that goniothalamin induced apoptosis and inhibited cell proliferation.

Another group is protein in MAPK signaling pathway playing important role both in cell survival and cell death. Conventional MAPKs in mammalian include the ERK1/2, JNK1/2 and p38. ERK1/2 activates Bax protein and caspase then deactivates Akt pathway, which leads to apoptosis. JNK1/2 can activate the transcriptional factors including c-Jun, which express Bim. p38 is tumor suppressor, which induce apoptosis and inhibit cell proliferation. p38 can activate p53, which is tumor suppressor (Fig. 6A). This result showed that goniothalamin induced p-ERK1/2, p-p38/p38 ratio and c-Jun upregulation in A375 treated cells leading to apoptosis. In general, ERK is important in cell proliferation, cell differentiation, cell growth or cell survival, however, we found that goniothalamin induced p-ERK1/2 upregulation in A375 treated cells. These results correlated with previous report by Tan et al, that ERK1/2 could activate caspase and pro-apoptotic protein in Bcl-2 family, moreover ERK1/2 could deactivated Akt signaling pathway leading to apoptosis induction (28). Therefore, the results showed that c-Jun and p-ERK1/2 were increased implying that goniothalamin induced apoptosis in A375 cell.

Indeed, we also confirmed the effect of goniothalamin on apoptosis induction through p-ERK1/2 activation using U0126. The results showed that goniothalamin induced apoptosis in A375 cells via ERK1/2 signaling (Fig. 6C). Our study correlated with previous report that ERK is involved in apoptosis induction of Moringa oleifera fruit (MOF) extract in human melanoma A2058 cells (29).

In summary, goniothalamin has an effect as anti-proliferation and apoptosis induction in A375 cells associated with upregulated p-ERK1/2, c-Jun and downregulated p-PDK1 (Ser241), total Akt in A375 cells. Studying the effect of Goniothalamin in other MM cell lines. In the future, the effect of goniothalamin in primary epidermal melanocytes (normal) will be studied to confirm that this compound could affect melanoma but not the normal cell. Furthermore the effect of goniothalamin should be studied in animal model.

\section{Acknowledgements}

We would like to thank Research Division, Faculty of Medicine, Research Unit in Biological Aactivities of Bioactive Compounds, Strategic Wisdom and Research Institute Srinakharinwirot University.

\section{References}

1. Lopez AD, Mathers CD, Ezzati M, Jamison DT and Murray CJ: Global and regional burden of disease and risk factors, 2001: Systematic analysis of population health data. Lancet 367 : 1747-1757, 2006.

2. Armstrong BK and Kricker A: The epidemiology of UV induced skin cancer. J Photochem Photobiol B 63: 8-18, 2001.

3. Diepgen TL and Mahler V: The epidemiology of skin cancer. $\mathrm{Br}$ J Dermatol 146 (Suppl 61): S1-S6, 2002. 
4. Strickland PT, Vitasa BC, West SK, Rosenthal FS, Emmett EA and Taylor HR: Quantitative carcinogenesis in man: Solar ultraviolet $\mathrm{B}$ dose dependence of skin cancer in Maryland watermen. J Natl Cancer Inst 81: 1910-1913, 1989.

5. Mukherjee AK, Basu S, Sarkar N and Ghosh AC: Advances in cancer therapy with plant based natural products. Curr Med Chem 8: 1467-1486, 2001

6. Ellis RE, Yuan JY and Horvitz HR: Mechanisms and functions of cell death. Annu Rev Cell Biol 7: 663-698, 1991.

7. Wiederschain G: Essentials of apoptosis. A guide for basic and clinical research. Springer, New York, NY, 2005.

8. Klein G: Cancer, apoptosis, and nonimmune surveillance. Cell Death Differ 11: 13-17, 2004

9. Kerr JF, Wyllie AH and Currie AR: Apoptosis: A basic biological phenomenon with wide-ranging implications in tissue kinetics. Br J Cancer 26: 239-257, 1972.

10. Sun T, Miao X, Zhang X, Tan W, Xiong $P$ and Lin D Polymorphisms of death pathway genes FAS and FASL in esophageal squamous-cell carcinoma. J Natl Cancer Inst 96: 1030-1036, 2004.

11. Mosaddik MA and Haque ME: Cytotoxicity and antimicrobial activity of goniothalamin isolated from Bryonopsis laciniosa. Phytother Res 17: 1155-1157, 2003.

12. Chiu CC, Liu PL, Huang KJ, Wang HM, Chang KF, Chou CK, Chang FR, Chong IW, Fang K, Chen JS, et al: Goniothalamin inhibits growth of human lung cancer cells through DNA damage, apoptosis, and reduced migration ability. J Agric Food Chem 59: 4288-4293, 2011.

13. Innajak S, Mahabusrakum $\mathrm{W}$ and Watanapokasin R Goniothalamin induces apoptosis associated with autophagy activation through MAPK signaling in SK-BR-3 cells. Oncol Rep 35: 2851-2858, 2016.

14. Portugal $\mathrm{J}$ and Waring MJ: Assignment of DNA binding sites for 4',6-diamidine-2-phenylindole and bisbenzimide (Hoechst 33258). A comparative footprinting study. Biochim Biophys Acta 949: 158-168, 1988.

15. Lecoeur H: Nuclear apoptosis detection by flow cytometry: Influence of endogenous endonucleases. Exp Cell Res 277: 1-14, 2002.

16. Pihie A, Stanslas J and Din LB: Non-steroid receptor-mediated antiproliferative activity of styrylpyrone derivative in human breast cancer cell lines. Anticancer Res 18: 1739-1743, 1998.

17. Al-Qubaisi M, Rosli R, Subramani T, Omar AR, Yeap SK, Ali AM and Alitheen NB: Goniothalamin selectively induces apoptosis on human hepatoblastoma cells through caspase-3 activation. Nat Prod Res 27: 2216-2218, 2013.

18. Wiart C: Goniothalamus species: A source of drugs for the treatment of cancers and bacterial infections? Evid Based Complement Alternat Med 4: 299-311, 2007.
19. Petsophonsakul P, Pompimon W and Banjerdpongchai R: Apoptosis induction in human leukemic promyelocytic HL-60 and monocytic U937 cell lines by goniothalamin. Asian Pac J Cancer Prev 14: 2885-2889, 2013.

20. Inayat-Hussain S, Annuar BO, Din LB, Ali AM and Ross D Loss of mitochondrial transmembrane potential and caspase-9 activation during apoptosis induced by the novel styryl-lactone goniothalamin in HL-60 leukemia cells. Toxicol In Vitro 17: 433-439, 2003.

21. De Fátima A, Modolo LV, Conegero LS, Pilli RA, Ferreira CV, Kohn LK and De Carvalho JE: Styryl lactones and their derivatives: Biological activities, mechanisms of action and potential leads for drug design. Curr Med Chem 13: 3371-3384, 2006.

22. Vendramini-Costa DB, Alcaide A, Pelizzaro-Rocha KJ, Talero E, Ávila-Román J, Garcia-Mauriño S, Pilli RA, de Carvalho JE and Motilva V: Goniothalamin prevents the development of chemically induced and spontaneous colitis in rodents and induces apoptosis in the HT-29 human colon tumor cell line. Toxicol Appl Pharmacol 300: 1-12, 2016.

23. Sophonnithiprasert T, Nilwarangkoon S, Nakamura Y and Watanapokasin R: Goniothalamin enhances TRAIL-induced apoptosis in colorectal cancer cells through DR5 upregulation and cFLIP downregulation. Int J Oncol 47: 2188-2196, 2015.

24. Alabsi AM, Ali R, Ali AM, Al-Dubai SA, Harun H, Abu Kasim NH and Alsalahi A: Apoptosis induction, cell cycle arrest and in vitro anticancer activity of gonothalamin in a cancer cell lines. Asian Pac J Cancer Prev 13: 5131-5136, 2012.

25. Chen WY, Wu CC, Lan YH, Chang FR, Teng CM and Wu YC: Goniothalamin induces cell cycle-specific apoptosis by modulating the redox status in MDA-MB-231 cells. Eur J Pharmacol 522: 20-29, 2005.

26. Sophonnithiprasert T, Mahabusarakam W, Nakamura Y and Watanapokasin R: Goniothalamin induces mitochondria-mediated apoptosis associated with endoplasmic reticulum stress-induced activation of JNK in HeLa cells. Oncol Lett 13: 119-128, 2017.

27. Sophonnithiprasert T, Mahabusarakam W, Nakamura Y and Watanapokasin R: Antiproliferation and apoptosis induction in colorectal cancer cells by goniothalamin. J Med Assoc Thai 98 (Suppl 9): S146-S151, 2015.

28. Tan BJ and Chiu GN: Role of oxidative stress, endoplasmic reticulum stress and ERK activation in triptolide-induced apoptosis. Int J Oncol 42: 1605-1612, 2013.

29. Guon TE and Chung HS: Moringa oleifera fruit induce apoptosis via reactive oxygen species-dependent activation of mitogen-activated protein kinases in human melanoma A2058 cells. Oncol Lett 14: 1703-1710, 2017. 